\title{
Professor, MÉTOdo E ALUNO NOS MÉTOdOS E ABORDAGENS \\ DE LÍNGUA ESTRANGEIRA
}

Magali SAddi Duarte*

\section{Resumo}

Este artigo, fundamentado em princípios teóricos que tratam da aquisição de segunda língua, faz uma revisão sobre os principais elementos que subsidiam o processo de ensino e aprendizagem de segunda língua, quais sejam: o professor, o aluno e o método, na perspectiva dessas teorias. Pensando no processo histórico de ensino e aprendizagem de segunda língua, vimos que a teoria ora polarizava no método, ora no professor, ora no aluno. Acreditamos que a questão não está na polarização, mas na possibilidade de triangulação (entrelaçamento) entre método, professor e aluno. Todos esses três elementos são categorias importantes para a compreensão e desenvolvimento do processo de aquisição de segunda língua.

PalaVras-CHAVE: abordagens, aquisição de segunda língua, métodos.

Teacher, method and student in the mehods and approaches of second language acquisition

\section{AbSTRACT}

This article, based on theoretical principles that deal with the acquisition of a second language, revises the main elements that underlie the process of teaching and learning a second language, from the perspective of these theories, that are: teacher, student, and method. When we think about the historical process of teaching and learning a second language, we notice that the theory sometimes focuses on the method, sometimes on the teacher, and sometimes on the student. We believe that the question is not on the polarization, but on the possibility of triangulation (interweaving) of all of them. The three elemens cited are important categories for the understanding and development of the process of second language acquisition.

KEY WORDS: approaches, methods, second language acquisition.

\section{INTRODUÇÃO}

O século passado foi palco de transformações no campo educacional. Sobre o ensino de segunda língua, no que diz respeito ao papel do professor, Volpi (2001, p. 126) afirma que

* Professora de língua inglesa do Centro de Ensino e Pesquisa Aplicada à Educação/ UFG.saddimagali@ig.com.br 
a função do professor se limitava à mera aplicação de um método ou à utilização de materiais didáticos previamente elaborados, e, como mero instrutor, transmitir os seus conhecimentos a partir de decisões tomadas sem sua participação direta e com o respaldo de teorias lingüísticas na maioria das vezes por ele desconhecida. O professor era considerado, assim, o único responsável pelo processo de ensino e o aluno um agente passivo. (Grifos do autor)

As rápidas transformações ocorridas na sociedade globalizada demandam um novo perfil de trabalhador, o que acabou por exigir mudanças no cenário educacional, principalmente no papel do professor de língua estrangeira (LE). Daí a necessidade, não de um transmissor de conhecimentos, mas de um mediador, facilitador do processo educativo que esteja atento e pronto para "atender as funções sociais mais abrangentes" (Volpi, 2001, p. 126). Como ressalta Martins Peris, citado por Volpi (2001, p. 126), "o ensino é o subsidiário da aprendizagem: o aluno aprende e é responsabilidade do professor facilitar ou possibilitar sua aprendizagem".

No desenvolvimento histórico do ensino de LE, vamos perceber claramente a mudança do papel do professor centralizador, modelador, detentor do conhecimento, para o professor facilitador, orientador desse processo.

Assim, nas teorias psicolingüística e sociointeracionista, o papel do professor é relativizado, pois passa a ser visto como mediadorlfacilitador/ orientador e o aluno torna-se responsável pelo seu aprendizado. Mas, para que isso aconteça, o facilitador deve-lhe fornecer os instrumentos necessários como material didático relevante, contexto situacional real, autenticidade na comunicação. Então, se ao professor cabe o papel de selecionar os recursos, a metodologia, o material didático, ao aluno cabe obter maior autonomia na construção, no desenvolvimento de sua competência lingüística.

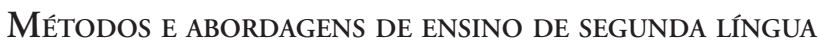
OU LÍNGUA ESTRANGEIRA

No panorama do ensino de LE, o paradigma behaviorista vigorou por muitos anos até o surgimento da teoria inatista de Chomsky. Apesar de o behaviorismo ter sido amplamente difundido por Skinner, seu primeiro teorizador foi Watson (Aguiar e Silva, 1977).

A história recente da metodologia do ensino de línguas fundamenta-se em duas correntes distintas: a) corrente estruturalista americana; e b) teoria inatista. A primeira representa o estruturalismo descritivista ame- 
ricano, mais tarde batizado por empirismo (Lima, 1981), ao passo que a segunda focaliza os fundamentos teóricos do inatismo chomskiano.

Ao tratarmos das correntes predominantes nas décadas de 1950 e 1960 - a corrente estruturalista americana e a teoria inatista -, queremos da primeira evidenciar a influência no ensino de LE e, da segunda, a importância que se opõe à lingüística estrutural, desmistificando o conceito de aprendizagem como o resultado de um processo de formação de hábitos.

O século XX foi palco de uma incessante busca de novos métodos e técnicas de ensino de LE, na tentativa de levar o aluno a uma maior proficiência. Desde o desenvolvimento do método direto, oficialmente aprovado na França e Alemanha na virada do século XVIII para o XIX (Richards e Rodgers, 2002), os estudiosos da área voltam-se para a descoberta de métodos que tenham como objetivo o produto, isto é, a língua a ser ensinada.

O método audiolingual, também conhecido como estruturalista e baseado na teoria psicológica behaviorista, desenvolveu-se na América do Norte, durante a Segunda Guerra Mundial, com a finalidade de ensinar aos soldados americanos as línguas estrangeiras dos países aliados e, também, dos países inimigos.

Para os estruturalistas, o aprendizado de línguas é o resultado do comportamento de hábitos adquiridos pelo condicionamento. Os cinco princípios básicos que caracterizam o método audiolingual foram muito difundidos, a ponto de se tornarem slogans. Vários lingüistas citam esses slogans, entre eles Girard (1976), Lima (1981) e Omaggio (1986): 1. A língua é a língua falada, não a língua escrita; 2 . Uma língua é um conjunto de hábitos; 3. Ensinar a língua e não sobre a língua; 4. Uma língua é o que dizem os autóctones e não o que se julga que eles deveriam dizer; 5. As línguas são diferentes.

Lima (1981, p. 28-29) comenta que "os pioneiros que estruturaram o método audiolingual se basearam em várias idéias correntes na época sobre a modernização do ensino de línguas estrangeiras para estabelecer os princípios básicos desse método", a saber:

a) Dar ênfase à língua falada, não apenas como um objetivo a atingir mas também como instrumento da transmissão dos conhecimentos na sala de aula.

b) Colocar a capacidade de ouvir como primeiro objetivo a atingir, antes da capacidade de falar, tanto do ponto de vista da discriminação de fo- 
nemas, como da compreensão de enunciados completos; ouvir e falar precedem as capacidades de ler e escrever sempre que um novo tópico, estrutura ou padrão, é introduzido.

c) Restringir o uso da língua nativa do aluno ao mínimo possível e desencorajar a tradução como uma técnica em si.

d) Evitar declarações explícitas por parte do professor acerca da natureza do que está sendo aprendido pelo aluno.

e) Enfatizar a mímica, a memorização de diálogos especificamente preparados e a substituição repetitiva de padróes estruturais.

f) Procurar, sempre que possível, introduzir os tópicos de cada lição em uma série cuidadosamente controlada e graduada em dificuldade, baseados em uma análise sistemática da língua a ser aprendida.

g) Utilizar a análise constrativa da língua nativa dos alunos e da língua estrangeira, quando todos os alunos de uma turma falarem a mesma língua. (Lima, 1981, p. 29)

Ainda no método audiolingual, deve-se evitar o erro. Para os behavioristas, o erro é visto como algo negativo na aprendizagem de segunda língua.

Então, vemos que, nesse período em que se passou a adotar o método audiolingual, a centralidade do processo de ensino e aprendizagem estava no método. O professor era um modelador da língua-alvo em sala de aula, e ao aluno cabia a tarefa de imitar e repetir o input apresentado em sala.

Conforme assinala Lima (1981), por volta de 1975, o audiolingualismo começa a ser questionado pelos educadores, uma vez que ele não atingiu o objetivo proposto de capacitar o aluno para o uso comunicativo da língua estrangeira.

Em 1957, surge a teoria transformacional, com o lingüista e ativista político Noam Chomsky, que se opõe ao princípio de que a língua é essencialmente comportamento (Skinner, 1978), rompendo com o paradigma até então vigente, a teoria psicológica behaviorista. Para Chomsky, a teoria do comportamento não explica o fato de a criança, por exemplo, ser capaz de emitir um número considerável de frases novas às quais ainda não havia sido exposta. Chomsky (1999, p. 24) remete-se à faculdade da linguagem, que é um componente inato da mente/cérebro humano, definindo-a como sendo um

sistema biológico adaptado a uma tarefa "expressiva": a de fornecer expressões que possam ser usadas pelo ser humano para falar sobre o mundo, 
descrever, referir, perguntar, exprimir "atitudes proposicionais" (ou seja, atitudes subjectivas como crenças, receios, alegrias, esperanças, desejos, etc.), comunicar com outros (muitas vezes sem transmitir informação nova), articular pensamentos para si próprio, e tudo o mais que podemos fazer com a linguagem (como por exemplo insultar, exprimir profunda ignorância, fazer-se passar por ridículo, enganar o povo, entre outras coisas num registo menos nobre).

Dessa forma, a faculdade da linguagem constitui-se de dois sistemas: o cognitivo, em que as informações são armazenadas; e o de desempenho, que tem acesso a essas informações e, também, a possibilidade de usá-las.

Apesar de Chomsky não ter se ocupado da aquisição de LE, a sua teoria muito contribuiu para um maior entendimento sobre o processo ensino e aprendizagem de línguas. Figueiredo (1997, p. 14-15) apresenta os principais argumentos desenvolvidos por Chomsky sobre a inadequação do paradigma behaviorista:

a) a língua não é meramente um "comportamento verbal", mas sim um complexo sistema de regras. Essas regras referem-se às hipóteses sobre os conhecimentos que habilitam os falantes a produzirem frases ou seqüências de palavras de maneira tal que essas frases e seqüências são compreensíveis e reconhecidas como pertencendo a uma língua, a maioria das quais não foi por eles ouvida anteriormente. Esta "criatividade" não seria possível se tivéssemos de nos ater a um comportamento aprendido. Ela só é possível porque temos a capacidade de internalizar um sistema de regras de uma língua a qual estejamos expostos. Segundo Chomsky (Aspectos da teoria da sintaxe, 1978) o conhecimento dessas regras é nossa "competência lingüística", e a realização desse conhecimento através do nosso discurso é o que o autor chama de "desempenho";

b) a partir da fala no ambiente, a criança elabora hipóteses sobre a língua, ou seja, um conhecimento abstrato de regras (ou "competência"). Entretanto, a criança não está exposta a essas regras, mas sim à fala das pessoas. Este processo de extrair conhecimento abstrato (regras) a partir de exemplos concretos (fala) não pode ser explicado pela formação de hábitos;

c) o reforço - um dos pressupostos básicos da abordagem behaviorista - tinha, segundo Chomsky, um papel secundário, pois freqüentemente os pais não corrigem os erros de pronúncia ou de gramática de seus filhos: o que mais lhes interessa é o que as crianças têm a dizer - se é verdadeiro ou adequado - e não especificamente as estruturas frasais que elas usam; 
d) apesar de as crianças serem expostas a diferentes discursos, elas constroem um sistema de regras comum a todas as crianças da comunidade na qual estão inseridas, ou seja, elas passam por seqüências basicamente semelhantes no processo de aquisição dessas regras. Novamente, isto não pode ser explicado pela formação de hábitos.

Na passagem da teoria behaviorista para a transformacionalista temse, também, uma sensível mudança no papel do professor. Se no behaviorismo ele se comportava como modelador, nesta nova perspectiva, ele passa a mediar o processo de ensino e aprendizagem de forma a levar o aluno a fazer deduçóes da estrutura da língua. $\mathrm{O}$ material didático passa a ser autêntico, isto é, sem fins didáticos, e o aluno deixa de ser imitador para ser criativo. $\mathrm{O}$ erro passa a ser visto como algo positivo no processo de aquisição de língua.

É nos meados dos anos 1960 que se iniciam "reações aos aspectos considerados críticos nas concepções estruturalistas e gerativo-transformacionais", isto é, a ausência de interesse, dessas concepções, nos aspectos sociais constitutivos da linguagem (Braggio, 1992, p. 27). Ainda segundo Braggio (1992), destacam-se, nesse cenário, a sociolingüística, a lingüística do texto e a psicolingüística. É nossa intenção, neste trabalho, discutir a sociolingüística e a psicolingüística, que mais recentemente vêm influenciando os estudos de lingüistas brasileiros.

Um dos pontos-chave para a sociolingüística no que se refere à teoria chomskiana é a noção de competência. Para Chomsky (1978), competência é o conhecimento que o sujeito possui da sua língua, sendo, portanto, o conhecimento do sistema da língua, incluindo as regras gramaticais, vocabulário e, ainda, como os elementos lingüísticos podem ser combinados para formar sentenças. O sociolingüista Hymes (1985) cunhou o termo "competência comunicativa" com o intuito de contrastar a visão comunicativa da linguagem à teoria da competência de Chomsky. A expressão competência comunicativa, em Hymes, se define pelo conhecimento das regras psicológicas sociais e culturais que regem os intercâmbios lingüísticos de uma determinada comunidade. A competência lingüística é parte integrante da competência comunicativa, porém esta última vai além do conhecimento de regras gramaticais, pois permite ao aprendiz saber "quando falar, quando não falar e, também, o que falar, com quem, em que momento, onde, de que maneira" (Hymes, 1985, p. 15). Conforme afirma Hymes, quando a criança normal adquire o conhecimento das ora- 
ções como itens gramaticais, o conhecimento das condiçôes de seu uso já está assegurado.

Savignon (1983, p. 8-9) elenca as características básicas da competência comunicativa como sendo

a) um conceito mais propriamente dinâmico que estático, que depende da negociação do significado entre duas ou mais pessoas que compartilham algum conhecimento da língua. Nesse sentido, então, pode-se dizer que a competência comunicativa é preponderantemente caracterizada como interpessoal;

b) mais que um fenômeno oral, pois implica também a linguagem escrita;

c) um acontecimento que ocorre numa situação particular ou num contexto específico;

d) relativa e dependente da cooperação de todos os envolvidos.

Com essa nova discussão, surge a abordagem comunicativa. O ensino comunicativo de línguas apresenta as seguintes características: a) a linguagem é um sistema para a expressão de significado; b) a função primeira da linguagem é a interação e a comunicação; c) a estrutura da língua reflete seus usos funcional e comunicativo; e d) as unidades primeiras da língua são categorias de significados funcional e comunicativo como exemplificados no discurso (Richards e Rodgers, 2002, p. 161).

O movimento comunicativo teve início na década de 1970 com Dell Hymes (1972), Wilkins (1976) e Widdowson (1978), conforme afirma Moll da Cunha (1992). Com base nesse movimento, que vai se sistematizar na abordagem comunicativa, outras abordagens se desenvolvem. Daí vários autores mencionarem atualmente uma abordagem eclética, pois, conforme salienta Savignon (1983), o fato de a abordagem comunicativa referir-se à habilidade de produzir significados fez com que os professores desenvolvessem técnicas e estratégias com o objetivo de colocar em foco o significado. Além disso, prossegue a autora, a ênfase, hoje, não é mais no método, mas no contexto. Segundo Savignon (1983), há um consenso geral de que não existe um único método adequado para satisfazer as necessidades dos aprendizes em todos os contextos.

O ensino comunicativo de línguas apresenta as seguintes características: a) a língua é um sistema para a expressão de significado; b) a função primeira da língua é a interação e a comunicação; c) a estrutura da língua reflete seus usos funcional e comunicativo; e d) as unidades da língua são 
categorias de significados funcional e comunicativo como exemplificados no discurso (Richards e Rodgers, 2002, p. 161).

No Brasil, Almeida Filho desenvolve projetos na linha da abordagem comunicativa, seguindo a corrente da escola britânica. Conforme afirma Vieira Abrahão (1996), Almeida Filho tem oferecido aos professores de LE uma orientação teórico-prática intitulada de tendência crítica do movimento comunicativo. Discípulo de Widdowson, Almeida Filho, citado por Bologinini (1991, p. 45) diz que

o ensino comunicativo é aquilo que não toma as formas da língua escrita nas gramáticas como o modelo suficiente para organizar as experiências de aprender outra língua, mas sim, aquele que toma unidades de ação feitas através da linguagem como organizatórias das amostras autênticas (ou pelo menos verossímeis) de língua-alvo que se vão criar com e oferecer ao aluno-aprendiz.

Segundo Savignon (1983), com a proposta do ensino de língua em contexto e com o foco no significado, há uma mudança na forma de ensinar. Deixam-se de lado os drills, as sentenças isoladas, e passa-se a privilegiar o texto. Da repetição, da análise gramatical, enfatizam-se, agora, a interpretação, a expressão, a negociação de sentido em situações da vida real.

Vieira Abrahão (1996, p. 62-63) apresenta os seguintes pressupostos teóricos da tendência crítica do movimento comunicativo:

$O$ aluno deve ser considerado o centro do processo ensino-aprendizagem, o objetivo do processo ensino-aprendizagem é promover tanto o desenvolvimento intelectual como o afetivo do aprendiz; o aluno deve ser estimulado a desenvolver sua autonomia frente ao processo ensino-aprendizagem, ou seja, deve aprender a assumir a responsabilidade de sua aprendizagem e do grupo; as atividades e tarefas a serem desenvolvidas em sala de aula devem ser verossímeis e selecionadas com a participação dos aprendizes. (Grifo nosso)

Seguindo essa tendência de ensino, autores como Costa (1987), van Ek (1985), Weininger (2001) e Nunan (1999), dentre outros, afirmam que as políticas de ensino devem estar em consonância com a necessidade do aluno. Volpi (2001, p. 126-127), citando Globe e Porter, explica que, nesse sentido, é preciso que o professor, entendido agora como orientador, faça um diagnóstico para calcular o "tipo de conhecimentos, habilidades 
e aspectos culturais das sociedades e das circunstâncias específicas onde o processo educacional há de desempenhar-se". Weininger (2001, p. 45) entende que, para haver uma mudança no processo de ensino-aprendizagem de língua estrangeira, é preciso primeiramente que o professor mude. Para tanto,

[...] o aluno, com seus interesses e suas necessidades comunicativas, deve estar no centro do processo de aprendizagem de lingua estrangeira. $\mathrm{O}$ aluno não deve ser objeto do processo de aprendizagem e dos esforços do professor, empenhado em aplicar "vacina" e "injeçōes" sintáticas em alta dosagem diretamente no cérebro dos estudantes, junto a treinos de sobrevivência situacional, para deixá-los aptos a enfrentarem os desafios da comunicação autêntica no novo idioma. A aula não deve privilegiar mais o professor, nem o material didático. (Grifos nossos)

A interação e o papel do professor assumem uma importância singular nos estudos desenvolvidos pela lingüística aplicada, nesta última década. Assim, o ambiente e as atividades propostas adquirem uma dimensão determinante no processo avaliativo do desempenho de ensino. Relativizase, então, a importância de elementos como planejamento lingüístico, bem como o ensino em si e enfatiza-se a participação de alunos na co-produção de uma aula, além da importância da interação, pois que é o próprio processo de desenvolvimento lingüístico (Costa, 1987).

Weininger (2001, p. 59) é enfático quando se refere à necessidade de desenvolver mais a questão da aprendizagem em detrimento do ensino. Defensor da abordagem construtivista, ele afirma que, nesta abordagem, o professor deixa de transmitir e "aplicar pacote de material didático" e passa a levar os alunos a interagir com materiais do mundo real. Em outras palavras, o professor organiza e gerencia aquilo que pode levar o aluno à aprendizagem, não se esquecendo de trabalhar em contextos reais da língua e da cultura-alvo.

Nesse contexto, há autores que defendem não a polarização em uma única categoria, como a proposta de Weininger (2001), mas a sensatez de trabalhar todos os elementos necessários para o desenvolvimento de qualquer aprendizagem. Torres $(1994$, p. 62), por exemplo, afirma que

ensino-aprendizagem constituem [sic] uma unidade dialética. O ensino é realizado na aprendizagem (mas o inverso não é verdade). No conceito de ensino está incluído o de aprendizagem. Ensino sem aprendizagem não é 
ensino, é um absurdo. E é esse o absurdo básico no qual continua funcionando o sistema educativo; o ensino, em algum momento, passou a ganhar autonomia em relação à aprendizagem: criou seus próprios métodos, seus próprios critérios de avaliação e auto-avaliação (considera-se "ensinado" na medida em que o programa foi cumprido ou que se cumpriu com as horas-aula etc.; não na medida em que o aluno aprende efetivamente). Desta forma, trataria-se [sic] agora mais de restituir a unidade perdida entre ensino e aprendizagem, de voltar a juntar o que nunca deveria ter-se separado, de restituir, no final das contas, o significado de ensino. Colocar a situação em termos de "concentrar a atenção na aprendizagem" pode levar ao mesmo erro que antes levou o "concentrar a atenção no ensino".

A teoria psicolingüística de Vygotsky, também conhecida como teoria sociocultural, cujo objetivo é "investigar e explicar o desenvolvimento cognitivo das crianças” (Figueiredo, 2001, p. 60), exerce significativa influência na lingüística aplicada, principalmente nos estudos sobre aquisição de segunda língua.

Para Vygotsky, citado por Figueiredo (2001, p. 23), "o pensamento verbal é um processo histórico-cultural obtido por meio de interaçôes significativas das crianças com os membros de sua comunidade sociolingüística" (grifos nossos).

Há, nesta teoria, uma centralidade no aspecto interacional no que se refere à aquisição de línguas. Isso se verifica no que Vygotsky chamou de zona de desenvolvimento proximal (ZDP). De acordo com o autor, a criança possui dois níveis de desenvolvimento, a saber: o real e o potencial. Se, no primeiro, a criança desenvolve certas tarefas independentemente, no segundo, ela conta com a ajuda de outra pessoa.

Com a sociolingüística e a psicolingüística tem-se, então, um rico cenário de pesquisas sobre o ensino de LE, em que as fronteiras já não são mais delimitadas. Daí a afirmação de Harste, citado por Braggio (1992, p. 68): "um novo paradigma está evolvendo [já que] nas ciências sociais os paradigmas raramente substituem um ao outro; antes o velho e o novo vivem lado a lado".

Com base na teoria psicolingüística, tem-se ainda "a aprendizagem cooperativa", cujo nome evidencia a centralidade não no ensino mas na aprendizagem. Importa-nos descrever um pouco dessa abordagem, pelo destaque que vem obtendo mais recentemente no ensino de LE por meio de pesquisas (Donato, 1994; Figueiredo, 2001). 
A centralidade dessa abordagem está no papel colaborativo que o aluno exerce no processo de aquisição de segunda língua. Nesse sentido, a aprendizagem cooperativa dá um novo enfoque à aprendizagem de LE, ao objetivar mais a colaboração que a competição. Verifica-se então uma mudança no comportamento do professor, que passa a exercer o papel de facilitador, conforme afirmam Olsen e Kagan, citados por Figueiredo (2001, p. 70).

A abordagem colaborativa, que tem seus princípios básicos na psicolingüística, não deixa de ser uma extensão da abordagem comunicativa, cuja centralidade está na interação e no significado. Na aprendizagem cooperativa, os alunos buscam resultados positivos para eles próprios e para todos os membros do grupo.

McGroarty, citado por Richards e Rodgers (2002, p. 195), mostra seis vantagens da aprendizagem de inglês como segunda língua na perspectiva da aprendizagem cooperativa:

1) aumento de freqüência e variedade de prática na segunda língua por meio de diferentes tipos de interação;

2) possibilidade de desenvolvimento ou uso da língua de modo a dar suporte ao desenvolvimento cognitivo e aumentar as habilidades da língua;

3) oportunidades para integrar a língua com a abordagem baseada em conteúdos;

4) oportunidades de incluir uma grande variedade de materiais curriculares para estimular a língua, assim como o conceito de aprendizagem;

5) liberdade para os professores lidarem com novas habilidades profissionais, em particular aquelas que enfatizam a comunicação;

6) oportunidades para os alunos agirem como fonte um para o outro, assumindo, então, um papel mais ativo em suas aprendizagens.

Além disso, podemos acrescentar a constatação de Figueiredo (2001, p. 67), de que "a interação não ajuda apenas os alunos menos experientes: ela leva, também, os alunos mais experientes a descobrirem novas formas de aprender".

\section{CONSIDERAÇÕES FINAIS}

Ao percorrermos a trajetória desenvolvida pelas teorias que deram origem às principais abordagens e métodos de ensino de língua estrangeira 
(LE), lembramos que, até o momento, as abordagens primam ora por enfatizar o método, ora o papel do professor e ora o papel do aluno.

Tendências contemporâneas de ensino de LE, contudo, fundamentadas na sociolingüística e na psicolingüística, têm discutido muito a questão do contexto, da interação e, nesse segundo item, a ênfase recai sobre o aluno, mas sem abrir mão da importância do papel desses três elementos, quando se trata da questão do ensino e aprendizagem de LE.

Neste novo século (XXI), precisamos ser mais cautelosos nas nossas afirmações, uma vez que o século passado já experimentou e sugeriu mudanças de um pólo para o outro sem muito sucesso.

O que nos anima em relação ao atual estágio das pesquisas realizadas no campo da lingüística aplicada é o fato de elas poderem mostrar os efeitos positivos que as várias teorias desenvolvidas têm trazido para esta área, ainda com muito a ser descoberto.

Como vimos ao longo deste trabalho, o papel do professor e do aluno, no método audiolingual, tinha muito pouca contribuição no processo de ensino e aprendizagem de LE.

Já no inatismo, há uma mudança tanto no papel do professor quanto no do aluno e no material a ser utilizado. Uma vez que esta teoria não se ocupou da aquisição de LE, não temos na literatura maior discussão sobre esses elementos.

$\mathrm{Na}$ sociolingüística e na psicolingüística, tem-se um maior entrelaçamento entre os três elementos: professor, método e aluno. Ainda que ambas as teorias enfatizem a centralidade no aluno, o material da primeira deve ser rigorosamente selecionado para atender às necessidades do aluno. O professor deixa de ser centralizador do processo e passa a ser mediador. O conteúdo deve ser autêntico, real. E, na psicolingüística, a ênfase, também, é no aluno, uma vez que o princípio básico dessa corrente é a interação. Mas, por entendermos que os princípios dessas teorias são bastante coerentes, pelo menos no que diz respeito à seleção de material, e por se fundamentarem na interação e no significado, podemos inferir que elas são as que melhor traduzem a possibilidade de atingir resultados positivos no processo de aquisição de LE.

Conhecidas as teorias e discutidas as abordagens, cabe ao professor repensar seu papel de orientador, mas também se preparar para a seleção de materiais e de estratégias a serem utilizadas, em sala de aula, para que os resultados sejam cada vez mais satisfatórios. 


\section{REFERÊNCIAS}

AGUIAR E SILVA, V. M. de. Competência lingüistica e competência literária. Coimbra: Livraria Almedina, 1977.

BOLOGNINI, C. Z. Livro didático: cartão-postal do país onde se fala a língua-alvo? Trabalhos de Lingüistica Aplicada. Campinas, v. 17, p. 43-53, jan/jun. 1991.

BRAGGIO, S. L. B. Leitura e alfabetização: da concepção mecanicista à sociolingüística. Porto Alegre: Artes Médicas, 1992.

CHOMSKY, N. Aspectos da teoria da sintaxe. 2. ed. Coimbra: Armênio Amado, 1978.

. O programa minimalista. Lisboa: Editorial Caminho, 1999.

COSTA, D. M. N. da. Por que ensinar língua estrangeira na escola de $1^{o}$ grau. São Paulo: EPU, Educ, 1987.

DONATO, R. Collective scaffolding in swecond language learning. In: LANTOLF, J. P.; APPEL, G. (Ed.). Vygotskian approaches to second language Learning. Norwood, N. J.: Ablex Publishing Company, 1994.

FIGUEIREDO, F. Q. de. Aprendendo com os erros: uma perspectiva comunicativa de ensino de línguas. Goiânia: Editora UFG, 1997.

- Correção com os pares: os efeitos do processo da correção dialogada na aprendizagem da escrita em língua inglesa. 2001. Tese. (Doutorado em Letras: Estudos Lingüísticos) - Universidade Federal de Minas Gerais, Belo Horizonte, Minas Gerais, 2001.

GIRARD, D. As línguas vivas: ensino e pedagogia. Coimbra: Almedina, 1976.

HYMES, D. On communicative competence. In: BRUMFIT, C. J.; JOHNSON, K. (Org.). The communicative approach to language teaching. London: Oxford University Press, 1985.

LIMA, E. M. de. Teoria transformacional e ensino de linguas. Rio de Janeiro: Ao Livro Técnico, 1981.

MOLL DA CUNHA, W. Reflexões sobre o papel da reflexão na educação de professores de inglês como segunda língua. 1992. Dissertação (Mestrado em 
Lingüística Aplicada ao Ensino de Línguas) - PUC-São Paulo, São Paulo, 1992.

NUNAN, D. Second language teaching \& learning. Boston: Heinle \& Heinle Publishers, 1999.

OMAGGIO, A. C. Teaching language in context. Boston: Heinle \& Heinle Publishers, 1986.

RICHARDS, J. C.; RODGERS, T. S. Approaches and methods in language teaching. New York: Cambridge University Press, 2002.

SAVIGNON, S. J. Communicative competence: theory and classroom practice. Reading, Massachussets: Addison-Wesley Publishing Company, Inc., 1983.

SKINNER, B. F. Comportamento verbal. São Paulo: Cultrix, 1978.

TORRES, R. M. Que (e como) é necessário aprender. 2. ed. Campinas: Papirus, 1994.

VAN EK. The treshold level. In: BRUMFIT, C. J.; JOHNSON, K. (Org.). The communicative approach to language teaching. London: Oxford University Press, 1985. p. 103-121.

VIEIRA ABRAHÃO, M. H. Conflitos e incertezas do professor de língua estrangeira na renovação de sua prática de sala de aula. 1996. Tese. (Doutorado em Lingüística Aplicada) - Instituto de Estudos da Linguagem, Universidade Estadual de Campinas, Campinas, SP, 1996.

VOLPI, M. T. A formação de professores de língua estrangeira frente aos novos enfoques de sua função docente. In: LEFFA, V. (Org.). O professor de linguas estrangeiras: construindo a profissão. Pelotas: Educat, 2001. p. 41-66.

WEININGER, M. J. Do aquário em direção ao mar aberto: mudanças no papel do professor e do aluno. In: LEFFA, V. (Org.). O professor de linguas estrangeiras: construindo a profissão. Pelotas: Educat, 2001. p. 41-66.

Recebido em: 18 jan. 2005. Aceito em: 9 jun. 2005. 